\title{
Staff Psychological Contract Innovates Human Resource Management
}

\author{
Xiaoyan LIU, Xin WEI \\ School of Management and Economics, Guangdong University of Technology, Guangzhou, China
}

\begin{abstract}
This paper mainly studies on the relationships between the contents of staff psychological contract, job satisfaction level and occupation satisfaction level by surveying, combining research methods of literature, academic and empirical research. The research results have important reference value on human resource management innovation. New suggestions were also put forward, which are relative with recruitment, measure of psychological contract, culture construction and targeted incentives to staff of different attributes.
\end{abstract}

Keywords: psychological contract, job satisfaction level, human resource management

\section{1 引言}

在競爭及全球化加速進行的當今社會, 唯有保有 人才才能為組織創造財富, 才能確保企業的飛速發 展。越來越多的企業都清楚認識到 “人才是決定企業 成敗的關鍵因素”。全面認識人才、培育人才、用好 人才、實現人才價值鏈, 對企業當前和未來的發展都 具有重大意義。目前理論界關於雇主與員工關係的研 究表明, 雇主與員工之間除了通過正式的、書面的勞 動合同建立的關係之外, 更重要的是一種內在的、未 公開說明的、非正式的相互期望和理解, 這種關係就 是 “心理契約 (psychological contract)”。在中國特殊 文化背景下, 心理契約的重要性遠遠超過書面合同, 它對企業人力資源管理起著基礎性和決定性的作用, 而心理契約的變化也將直接導致人力資源管理重心的 轉移和方式的創新。

\section{2 員工心理契約概述}

員工心理契約是雇員處於對組織政策、時間和文化的 理解和各級組織代理人作出的各種形式承諾的感知而 產生的, 對其與組織之間的、並不一定被組織各級代 理人所明確意識到的相互義務的一系列信念。心理契 約是一種不完全、動態性的契約形式, 具有主觀性的

About the author: ${ }^{1}$ Xiaoyan Liu, (1982-), female, Native place: Zhenzhou, Henan Province, master, mainly engaged in human resources management research; ${ }^{2}$ Xin Wei, (1965-), female, Native place: Meizhou, Guangdong Province, professor, mainly engaged in human resources management research.
特點，心理契約的違背受道德因素的制約，後果具有 不確定性。

\section{3 編制調查問卷}

近年來在全球競爭和技術革新的大背景下，心理 契約的內容構成發生了巨大變化，本文根據文獻分析 和對部分企業員工的實地調研訪談, 首先總結出心理 契約的三十六項內容，在對六家企業發放六十份問捲 進行預試調查之後，經過信度和效度分析，收集被調 查者的建議, 將心理契約內容的三十六個專案進行刪 減和語言上的調整, 最終歸納為以下二十六項: 1) 提 供有競爭力的工資；2）提供醫療、失業、工傷保險等 福利；3）提供其他福利: 如帶薪假期、獎勵旅遊等; 4）能夠按時發放工資；5）提供加薪調資的機會; 6) 薪 酬要與工作表現和成績掛鈎；7）提供工作所需的設 備、資訊等資源；8）安全舒適的工作環境；9）工作 穩定有保障；10）提供個人發展的空間；11) 在提升 和發展機會等方面公平對待；12) 經常開展職業培 訓；13）提供發展新技能的機會；14）給我明確的工 作職責和目標；15）給我與工作職責相應的自主權;

16）對我個人表現及時給予建設性回饋；17）經常瞭 解我在工作中的問題和困難, 及時做協調解決 ; 18) 適時公佈、解釋本單位的相關決策和發展計畫; 19) 重 視我提出的意見和建議；20）與同事、上下級之間能 夠開放、真誠地交流；21) 領導給予信任和尊重；22) 工作中能獲得來自上級的支援；23) 組織豐富的文化 娛樂活動；24）靈活的工作時間；25）周圍同事都很 勝任工作；26) 決策時考慮員工的利益。 
表 1. 問卷調查的對象及發放回收數量

Table 1. The interviewees and the quantity of distributing and receiving

\begin{tabular}{ccc}
\hline 發放對象 & 發放數量 $($ 份 $)$ & 收回有效問卷數量 $($ 份) \\
\hline MBA 學員 & 50 & 47 \\
成人教育在職學生 & 100 & 91 \\
H\&T LOGISTIC LTD. & 55 & 49 \\
中鐵快運 & 25 & 19 \\
中脈科技集團 & 25 & 17 \\
聖保羅門業 & 25 & 20 \\
某外資貿易公司 & 20 & 13 \\
總計 & 300 & 260 \\
\hline
\end{tabular}

\section{4 問卷調查與分析}

\section{1 調查對象與問卷回收}

接下來對廣東省五家不同性質、不同行業的企 業、某大學的在職 MBA 學員、成人教育的在職學員 等發放 300 份調查問卷, 內容包括員工對所在單位應 承擔的 26 項責任的重視程度、對所在單位這些專案完 成情況的評價, 以及員工的工作滿意度、職業滿意度、 基本資訊等。問卷調查的對象及發放回收數量如表 1 所示。

問卷有效回收率為 $86.67 \%$, 信度和效度均符合要 求, 經過探索性因數分析, 將心理契約違背 (心理契 約違背=重要性得分-實際履行得分) 分為四個因數: 交易因數、文化因數、工作支援因數和環境因數。運 用 SPSS 統計工具進一步進行描述性統計分析、方差 分析、相關性分析和回歸分析, 得到以下統計結果:

\section{2 統計分析結果}

\subsection{1 分析結果一}

員工認為最重要的十項心理契約內容中, 有七項 如 “提供個人發展的空間” 、“在提升和發展機會等 方面公平對待”、“提供醫療、失業、工傷保險等福 利”、“提供加薪調資的機會”、“薪酬要與工作表 現和成績掛鈎”、“決策時考慮員工的利益” 和 “提 供有競爭力的工資” 都在員工感到心理契約最違背的 十項中, 表明員工感知到雇主 (組織) 心理契約違背 是比較嚴重的;

\subsection{2 分析結果二}

不同性別、年齡、學歷、單位性質、工作類別、 職位級別、工齡和收入的員工, 心理契約違背和工作 滿意度有所差別, 結論如下: 1) 不同性別的員工在文
化因數、內在滿意度上有顯著性差異, 女性在文化因 數方面違背的程度大於男性, 說明女性比男性員工更 重視所在單位的文化氛圍; 而男性員工的工作內在滿 意度大於女性；2）不同年齡段的員工只有在文化因數 上存在明顯差異, 25 歲及以下的員工文化因數違背程 度最大, 並且與其他三個年齡段的員工之間有顯著性 差異, 總的來說年齡越大對文化方面越容易得到滿 足；3）不同學歷的員工在文化因數和外在滿意度上有 顯著性差異, 對文化因數違背程度最大的是大專學歷 的員工, 違背程度最小的是初中及以下學歷的員工, 對外在滿意度最高的是初中及以下學歷的, 總的來說 學歷最低和最高的員工相對滿意度較高, 而中等學歷 的員工滿意度較低；4）對員工心理契約違背、工作滿 意度和職業滿意度影響最大的因素是單位性質, 不同 單位性質的員工在心理契約違背、交易因數、文化因 數、環境因數、內在滿意度和外在滿意度上都有顯著 性差異, 方差分析結果如表 2 所示。5) 不同工作類別 的員工在交易因數和文化因數上有顯著差異, 職能管 理類員工在交易因數上的違背程度最大，市場行銷類 員工的違背程度最小; 在文化因數上, 則是職能管理 類員工的違背程度最小, 服務操作類的違背程度最 大；6）不同職位級別的員工在文化因數、外在滿意度 和職業滿意度上存在著明顯差異, 隨著職位升高員工 在文化因數上的違背程度基本是越來越低, 而外在滿 意度和職業滿意度則是越來越高; 7) 不同工作年限的 員工在工作外在滿意度上有顯著性差異, 除了工齡在 一年及以內的員工較低以外，工作一年以上的員工則 是隨著工齡增加外在滿意度越來越低; 8) 不同收入水 準的員工在文化因數、外在滿意度和職業滿意度上存 在明顯差異, 年薪越高外在滿意度和職業滿意度就越 高; 在文化因數上年薪 2 萬以下的員工違背程度最 大, 基本是隨著年薪增加而違背程度越小。 
表 2. 不同單位性質的方差分析

Table 2. One-way ANOVA analysis regarding corporation ownership system

\begin{tabular}{|c|c|c|c|c|c|c|}
\hline 項目 & 單位性質 & 樣本數 & 均值 & 標準差 & F值 & 顯著性 \\
\hline \multirow{5}{*}{ 心理契約違背 } & 國有企業 & 93 & -.1958 & .62670 & \multirow{5}{*}{2.835} & \multirow{5}{*}{0.025} \\
\hline & 民營企業 & 94 & .1187 & .65548 & & \\
\hline & 外資企業/合資企業 & 52 & .1187 & .96479 & & \\
\hline & 國家機關/事業單位 & 15 & .0565 & .49172 & & \\
\hline & 其他 & 6 & .0050 & .31594 & & \\
\hline \multirow{5}{*}{ 工作支持因數 } & 國有企業 & 93 & -.19328 & .869069 & \multirow{5}{*}{1.472} & \multirow{7}{*}{0.211} \\
\hline & 民營企業 & 94 & .13907 & .903126 & & \\
\hline & 外資企業/合資企業 & 52 & .04047 & 1.38872 & & \\
\hline & 國家機關/事業單位 & 15 & .17598 & .762552 & & \\
\hline & 其他 & 6 & .02633 & .513007 & & \\
\hline \multirow{5}{*}{ 交易因數 } & 國有企業 & 93 & -.19049 & .931059 & \multirow{5}{*}{2.654} & \\
\hline & 民營企業 & 94 & -.03560 & .970378 & & \\
\hline & 外資企業/合資企業 & 52 & .32254 & 1.10910 & & \multirow[t]{5}{*}{0.034} \\
\hline & 國家機關/事業單位 & 15 & .10014 & 1.06907 & & \\
\hline & 其他 & 6 & .46479 & .719565 & & \\
\hline \multirow{5}{*}{ 文化因數 } & 國有企業 & 93 & -.19192 & .860245 & \multirow{5}{*}{4.061} & \\
\hline & 民營企業 & 94 & .09698 & 1.00667 & & \\
\hline & 外資企業/合資企業 & 52 & .34953 & 1.09212 & & \multirow[t]{5}{*}{0.003} \\
\hline & 國家機關/事業單位 & 15 & -.55660 & .957545 & & \\
\hline & 其他 & 6 & -.18232 & 1.22443 & & \\
\hline \multirow{5}{*}{ 環境因數 } & 國有企業 & 93 & -.22612 & .786166 & \multirow{5}{*}{3.275} & \\
\hline & 民營企業 & 94 & .18371 & 1.04209 & & \\
\hline & 外資企業/合資企業 & 52 & .20271 & 1.13923 & & \multirow[t]{3}{*}{0.012} \\
\hline & 國家機關/事業單位 & 15 & -.23523 & .919995 & & \\
\hline & 其他 & 6 & -.54197 & 1.44549 & & \\
\hline \multirow{5}{*}{ 內在滿意度 } & 國有企業 & 93 & .30390 & .912976 & \multirow{5}{*}{5.433} & \multirow{5}{*}{0.000} \\
\hline & 民營企業 & 94 & -.20169 & .900336 & & \\
\hline & 外資企業/合資企業 & 52 & -.28298 & 1.16308 & & \\
\hline & 國家機關/事業單位 & 15 & .46998 & .935121 & & \\
\hline & 其他 & 6 & -.27301 & 1.03521 & & \\
\hline \multirow{5}{*}{ 外在滿意度 } & 國有企業 & 93 & .22290 & .934548 & \multirow{5}{*}{6.531} & \multirow{5}{*}{0.000} \\
\hline & 民營企業 & 94 & .13662 & .903391 & & \\
\hline & 外資企業/合資企業 & 52 & -.56885 & 1.09559 & & \\
\hline & 國家機關/事業單位 & 15 & -.14518 & .890641 & & \\
\hline & 其他 & 6 & -.30246 & 1.12784 & & \\
\hline \multirow{5}{*}{ 職業滿意度 } & 國有企業 & 93 & 3.0860 & .77538 & \multirow{5}{*}{1.962} & \multirow{5}{*}{0.101} \\
\hline & 民營企業 & 94 & 2.9894 & .76895 & & \\
\hline & 外資企業/合資企業 & 52 & 2.8077 & .81742 & & \\
\hline & 國家機關/事業單位 & 15 & 3.2000 & .67612 & & \\
\hline & 其他 & 6 & 2.5000 & .54772 & & \\
\hline
\end{tabular}


表 3. 員工心理契約違背四因數對工作滿意度的回歸分析結果

Table 3. Regressive analysis of psychological contract violation to job satisfaction Model Summary(e)

\begin{tabular}{|c|c|c|c|c|c|c|c|}
\hline \multirow[b]{2}{*}{ Model } & \multirow[b]{2}{*}{$\mathrm{R}$} & \multirow{2}{*}{$\begin{array}{c}\mathrm{R} \\
\text { Square }\end{array}$} & \multirow{2}{*}{$\begin{array}{l}\text { Adjusted R } \\
\text { Square }\end{array}$} & \multirow{2}{*}{$\begin{array}{l}\text { Std. Error of } \\
\text { the Estimate }\end{array}$} & \multicolumn{3}{|c|}{ Change Statistics } \\
\hline & & & & & $\begin{array}{l}\text { R Square } \\
\text { Change }\end{array}$ & F Change & $\begin{array}{l}\text { Sig. F } \\
\text { Change }\end{array}$ \\
\hline 1 & $.414(a)$ & .171 & .168 & .74695 & .171 & 53.067 & .000 \\
\hline 2 & $.489(b)$ & .239 & .233 & .71695 & .068 & 22.959 & .000 \\
\hline 3 & $.540(\mathrm{c})$ & .292 & .283 & .69315 & .052 & 18.883 & .000 \\
\hline 4 & $.584(\mathrm{~d})$ & .341 & .331 & .66977 & .050 & 19.109 & .000 \\
\hline
\end{tabular}

a Predictors: (Constant), 交易因數

b Predictors: (Constant), 交易因數、文化因數

c Predictors: (Constant), 交易因數、文化因數、工作支援因數

d Predictors: (Constant), 交易因數、文化因數、工作支援因數、環境因數

e Dependent Variable: 總的來說, 我對當前工作的滿意程度

\begin{tabular}{|c|c|c|c|c|c|c|}
\hline \multicolumn{7}{|c|}{ Coefficients(a) } \\
\hline & \multirow{2}{*}{ Model } & \multicolumn{2}{|c|}{$\begin{array}{l}\text { Unstandardized } \\
\text { Coefficients }\end{array}$} & \multirow{2}{*}{$\begin{array}{c}\begin{array}{c}\text { Standardized Coeffi- } \\
\text { cients }\end{array} \\
\text { Beta }\end{array}$} & \multirow{2}{*}{$\mathrm{t}$} & \multirow{2}{*}{ Sig. } \\
\hline & & B & Std. Error & & & \\
\hline \multirow[t]{2}{*}{1} & (Constant) & 3.137 & .046 & - & 67.588 & .000 \\
\hline & 交易因數 & -.340 & .047 & -.414 & -7.285 & .000 \\
\hline \multirow[t]{3}{*}{2} & (Constant) & 3.136 & .045 & - & 70.403 & .000 \\
\hline & 交易因數 & -.340 & .045 & -.415 & -7.609 & .000 \\
\hline & 文化因數 & -.214 & .045 & -.261 & -4.792 & .000 \\
\hline \multirow[t]{4}{*}{3} & (Constant) & 3.137 & .043 & - & 72.840 & .000 \\
\hline & 交易因數 & -.339 & .043 & -.413 & -7.839 & .000 \\
\hline & 文化因數 & -.213 & .043 & -.260 & -4.941 & .000 \\
\hline & 工作支持因數 & -.188 & .043 & -.229 & -4.345 & .000 \\
\hline \multirow[t]{5}{*}{4} & (Constant) & 3.137 & .042 & - & 75.380 & .000 \\
\hline & 交易因數 & -.339 & .042 & -.413 & -8.116 & .000 \\
\hline & 文化因數 & -.213 & .042 & -.260 & -5.116 & .000 \\
\hline & 工作支持因數 & -.188 & .042 & -.229 & -4.494 & .000 \\
\hline & 環境因數 & -.182 & .042 & -.223 & -4.371 & .000 \\
\hline
\end{tabular}

a Dependent Variable: 總的來說, 我對當前工作的滿意程度 


\subsection{3 分析結果三}

心理契約違背及其工作支援因數、交易因數、文 化因數、環境因數與工作滿意度和職業滿意度之間有 顯著的相關性, 呈負相關關係, 即心理契約的違背會 降低員工的工作滿意度和職業滿意度, 影響程度最大 的是交易因數, 其次是文化因數和工作支援因數, 影 響程度最小的是環境因數。員工心理契約違背對工作 滿意度的回歸分析結果如表 3 所示。

\section{5 對人力資源管理的創新}

以上員工心理契約的調查統計分析結果, 引起我 們對現代企業人力資源管理的重新思考。在企業的人 力資源管理工作中, 一定要重視員工與組織之間的心 理契約, 並加強認識和把握, 充分發揮心理契約在人 力資源管理中的積極作用, 減少違背帶來的危害。

\section{1 從招聘開始做好心理契約的創建管理}

招聘過程是個體與組織初次發生接觸的時候, 也 是員工心理契約形成的正式階段, 招聘宣傳會上的宣 講, 招聘手冊上的宣傳以及面試官的介紹都會讓求職 者對該單位及未來產生許多期望。對招聘單位來說, 要吸引優秀人才, 不能吹噓自身的優勢、員工未來的 權益等, 而對其劣勢和困難避而不談, 要全面、真實、 客觀地介紹企業的現狀, 避免新員工在正式進入企業 之後, 發現單位實際履行的責任與他們期望中的相差 很大, 引起嚴重的心理契約違背, 而對工作績效、員 工滿意度等產生負面影響。

\section{2 測量員工對心理契約的認知, 積極採取補償 措施}

心理契約是一種主觀的隱性契約, 是個體的, 也 是動態的, 每個員工與組織之間的心理契約都是不同 的, 同一個員工在不同階段的心理契約也會有所變化。 人力資源管理部門可以在新員工入職後, 協助部門主 管對新員工的心理契約內容進行調查, 並予以存檔, 一定時期後再組織測量, 發現有心理契約違背, 及時 瞭解原因, 如果是企業自身的過失, 管理者就可以解 釋、安撫, 或者有針對性地採取一些補償措施。有研 究表明, 新員工入職的前六個月是心理契約最容易遭 受違背的時期, 主要原因還在於新員工特別是剛剛參 加工作的應屆畢業生容易遭受現實衝擊, 對心理契約 違背的主觀認知比較強烈, 這就要求企業在對新員工 做入職培訓時, 增加對企業文化、價值觀及職業心態 方面進行教育, 並提供更多的機會讓新員工與老員工
多多交流獲取經驗。在目前全球經濟蕭條時期, 世界 各地企業員工都因擔心裁員降薪而志忈不安, 中國很 多民營企業的管理者非常重視員工心態的變化, 主動 提出 “不裁員、不減薪”, 甚至與員工簽訂了保證書, 這樣的舉措不僅使企業保留了人才, 更使員工對企業 的信任度和忠誠度加強, 形成了更加良好和穞固的心 理契約。

\section{3 重視企業的文化建設}

根據前文實證分析的結論, 文化因數是影響員工 工作滿意度的第二大因素, 特別是在中國的文化環境 中, 員工尤其重視組織的人際關係和文化氛圍。建議 企業盡可能創造和諧公平的氛圍, 管理者對下屬給予 信任和尊重, 經常指導員工的工作, 鼓舞他們的士氣, 並組織豐富的文化娛樂活動, 拉近員工之間的情感距 離, 增強員工對組織的歸屬感。此外, 在工作允許的 範圍內可以將工作時間調整得靈活一些, 這樣做並不 需要組織多投入很多資源, 對員工來說卻是一個不小 的福利。例如筆者所在的廣州某民營企業, 管理者非 常重視文化建設, 善於員工關係的柔性管理, 用愛心 和誠心培養人, 用宗教的道義薰陶人, 即使員工犯了 錯, 只要虛心改正就將損失當作交學費, 員工有工作 或生活上的困惑都可以找領導傾訴, 所以員工相處如 一家人, 人際關係非常融洽, 管理成本也很低。

\section{4 區別不同屬性的員工給予有針對性的激勵}

性別、年齡、學歷、單位性質、收入水準等因素 影響員工對心理契約違背的認知, 以及對工作滿意度 和職業滿意度的評價, 這對人力資源管理有一些重要 的啟示。針對不同屬性的員工企業應採取不同的激勵 方式, 分層分類管理,對於青年員工企業應給予他們更 多學習成長的機會, 幫助他們提升綜合能力。筆者所 在企業員工平均年齡在 30 歲以下, 學歷都在大專以上, 企業很注重培養員工多方面技能, 只要員工有意願, 就可以在多個崗位學習鍛煉, 雖然工資收入不高, 但 員工都很珍惜學習成長的機會, 所以員工忠誠度高, 流失率低, 當員工成長到能夠獨當一面時, 公司就鼓 勵該員工到全國甚至世界各地開設分支機搆, 幫助公 司拓展業務、發展壯大, 也為其個人提供了更廣闊的 發展空間。

前文調查統計分析結果還顯示: 各種屬性的員工 在文化因數上的差異最大，女性比男性員工更重視所 在單位的文化氛圍, 年齡越小的員工對文化因數違背 程度越大, 大專學歷的員工違背最大, 外資企業/合資 企業違背程度最大, 服務操作類的違背程度最大, 職 
位越低違背程度越大, 年薪 2 萬以下的違背程度最大, 隨著年薪增加而違背程度越小。因此, 如果企業中女 員工或者青年員工較多, 且學歷不低但收入不高時, 尤其要加強組織文化建設, 開展豐富多彩的文化娛樂 活動, 增加節假日福利, 派送生日禮物等等, 增強員 工對企業的歸屬感, 創建和諧的人際關係氛圍, 可以 提高員工的滿意度。

\section{6 結束語}

隨著經濟的發展、人類的進步,對企業的柔性管理 變得越來越重要,心理契約是企業柔性管理的重要方 面,把握員工心理契約的變化，做好人力資源管理的創 新, 將會提高勞資雙方的滿意度,促進企業形成和諧人 際關係，幫助企業更加穩定快速發展。

\section{REFERENCES}

[1] Anderson, N. and Schalk, R., "The psychological contract retrospect and prospect,” Journal of Organizational Behavior, Vol. 19, pp. 637-647, 1998.
[2] Rousseau, D. M., "New hire perspectives of their own and their employer's obligations: A study of psychological contracts,” Journal of Organizational Behavior, Vol. 11, No. 5, pp. 389-400, 1990.

[3] Robinson, S. L. and Rousseau, D. M., "Violation the psychological contract: Not the exception but the norm," Journal of Organizational Behavior, Vol. 15, pp. 145-159, 1994.

[4] Chen, J. Z., Ling, W. Q., and Fang, L. L., "Exploration and verification in staff psychological contract structural dimensions," Science and Science Technology Management, No. 3, 2004.

[5] Rousseau, D. M., "The problem of the psychological contract considered," Journal of Organizational Behavior, Vol. 19, pp. 661-671, 1998.

[6] Liu, F. Y. and Zhang, J.C., "Research on effectiveness of questionnaire of staff work satisfaction survey and influence factors of employees' job satisfaction in private enterprises,” Nankai Management Comment, No. 3, 2004.

[7] Wang, S. D., "Using psychological contract to improve the overall staff satisfaction,” Jilin: Master's degree thesis of Jilin University, 2005. 